\title{
Hydrogen Peroxide Production by the Spot-Like Mode Action of Bisphenol A
}

\author{
loannis-Dimosthenis S. Adamakis ${ }^{1 *}$, llektra Sperdouli ${ }^{2}$, Eleftherios P. Eleftheriou ${ }^{3}$ \\ and Michael Moustakas ${ }^{3 *}$
}

${ }^{1}$ Department of Botany, Faculty of Biology, National and Kapodistrian University of Athens, Athens, Greece, ${ }^{2}$ Institute of Plant Breeding and Genetic Resources, Hellenic Agricultural Organization Demeter, Thessaloniki, Greece, ${ }^{3}$ Department of Botany, Aristotle University of Thessaloniki, Thessaloniki, Greece

\section{OPEN ACCESS}

Edited by:

Vasileios Fotopoulos,

Cyprus University of Technology,

Cyprus

Reviewed by:

Qing Zhou,

Jiangnan University, China Manuel Joaquín Reigosa-Roger,

University of Vigo, Spain

*Correspondence:

Ioannis-Dimosthenis S. Adamakis iadamaki@biol.uoa.gr

Michael Moustakas

moustak@bio.auth.gr

Specialty section: This article was submitted to

Plant Abiotic Stress,

a section of the journal

Frontiers in Plant Science

Received: 09 April 2020

Accepted: 23 July 2020

Published: 05 August 2020

Citation:

Adamakis I-DS, Sperdouli I, Eleftheriou EP and Moustakas M

(2020) Hydrogen Peroxide Production by the Spot-Like Mode

Action of Bisphenol A.

Front. Plant Sci. 11:1196. doi: 10.3389/fpls.2020.01196
Bisphenol A (BPA), an intermediate chemical used for synthesizing polycarbonate plastics, has now become a wide spread organic pollutant. It percolates from a variety of sources, and plants are among the first organisms to encounter, absorb, and metabolize it, while its toxic effects are not yet fully known. Therefore, we experimentally studied the effects of aqueous BPA solutions (50 and $100 \mathrm{mg} \mathrm{L}^{-1}$, for 6,12 , and $24 \mathrm{~h}$ ) on photosystem II (PSII) functionality and evaluated the role of reactive oxygen species (ROS) on detached leaves of the model plant Arabidopsis thaliana. Chlorophyll fluorescence imaging analysis revealed a spatiotemporal heterogeneity in the quantum yields of light energy partitioning at PSII in Arabidopsis leaves exposed to BPA. Under low light PSII function was negatively influenced only at the spot-affected BPA zone in a dose- and timedependent manner, while at the whole leaf only the maximum photochemical efficiency (Fv/Fm) was negatively affected. However, under high light all PSIl photosynthetic parameters measured were negatively affected by BPA application, in a timedependent manner. The affected leaf areas by the spot-like mode of BPA action showed reduced chlorophyll autofluorescence and increased accumulation of hydrogen peroxide $\left(\mathrm{H}_{2} \mathrm{O}_{2}\right)$. When $\mathrm{H}_{2} \mathrm{O}_{2}$ was scavenged via $\mathrm{N}$-acetylcysteine under BPA exposure, PSIl functionality was suspended, while $\mathrm{H}_{2} \mathrm{O}_{2}$ scavenging under non-stress had more detrimental effects on PSII function than BPA alone. It can be concluded that the necrotic death-like spots under BPA exposure could be due to ROS accumulation, but also $\mathrm{H}_{2} \mathrm{O}_{2}$ generation seems to play a role in the leaf response against BPA-related stress conditions.

Keywords: bisphenol A, chlorophyll fluorescence imaging, plastoquinone pool, signaling molecule, $\mathrm{H}_{2} \mathrm{O}_{2}$ scavenger, photosystem II functionality, necrotic death-like spot, reactive oxygen species

\section{INTRODUCTION}

Plants are sessile organisms, specially affected by changes in their environment and therefore unavoidably prone to many stress-factors. So, plants have evolved an extensive range of mechanisms for acclimation and adaptation (van Loon, 2016). Numerous studies have confirmed that some of these mechanisms include reactive oxygen species (ROS) formation (Garg and Manchanda, 2009; 
Foyer, 2018; Huang et al., 2019). These molecules were traditionally related to wide-range damaging of cellular macromolecules (i.e., nucleic acids, lipids, proteins, etc.), which probably could result in cell death and even whole organism collapse (Potters et al., 2010). Nonetheless, decades of thorough research gathered substantial evidence to support that ROSmediated responses are orchestrated and regulated under a tight genetic control. Hence, in plants, ROS roles in early signaling events initiated by various environmental stimuli have been established (Noctor et al., 2018; Huang et al., 2019). These stimuli could include extreme temperatures (Awasthi et al., 2015), drought (Laxa et al., 2019), heavy metals (Eleftheriou et al., 2015), nanoparticles (Sperdouli et al., 2019), and organic pollutants (Christou et al., 2018).

One such organic pollutant is bisphenol A (2,2-bis(4hydroxyphenyl)propane; BPA), a chemical stabilizer widely applied in the industrial manufacture of plastic materials (Lin et al., 2017). As plastic commodities deteriorate, BPA can escape and pollute the environment ( $\mathrm{Xu}$ et al., 2011). This pollution seems to be harmful, since, BPA belongs to the xenoestrogen substance family and by acting as an endocrine disruptor can cause several human health issues (Jalal et al., 2018; Abraham and Chakraborty, 2019). While extensive research has been conducted about BPA effects on humans/animals, scientific data regarding the toxic effects of $\mathrm{BPA}$ on plants have been accumulating only in recent years (Xiao et al., 2020). Although plants can absorb and metabolize BPA, at the same time BPA could deteriorate their cellular/physiological status (Zhang et al., 2017). It has been shown that experimentally applied concentrations of BPA $(\mathrm{mg} / \mathrm{L})$ negatively affected the growth of many important crops, e.g., soybean (Qui et al., 2013; Zhang et al., 2016; Jiao et al., 2017; Li X. et al., 2018; Zhang et al., 2018; Xiao et al., 2019), pea (Adamakis et al., 2013), wheat (Adamakis et al., 2019), maize (Stavropoulou et al., 2018), rice (Ali et al., 2016), cucumber (Li Y. T. et al., 2018) and onion (Adamakis et al., 2019); also of non-cultivated plants such as the Cephalonian fir (Adamakis et al., 2016) and the model plant Arabidopsis thaliana (Pan et al., 2013; Tian et al., 2014; Frejd et al., 2016; Ali et al., 2017; Rapala et al., 2017; Bahmani et al., 2020). Growth reduction effects have interestingly been found to occur also after environmentally relevant concentrations $(\mu \mathrm{g} / \mathrm{L})$ applied on cultivated crops, e.g., cabbage and tomato (Staples et al., 2010), native plants such as oat (Staples et al., 2010) and seagrasses (Adamakis et al., 2018; Malea et al., 2020).

BPA-derived growth defects have been linked to either cytoskeletal derangement (Adamakis et al., 2013; Adamakis et al., 2016; Adamakis et al., 2018; Stavropoulou et al., 2018; Adamakis et al., 2019), hormonal imbalance (Frejd et al., 2016; Li X. et al., 2018; Bahmani et al., 2020), deterioration of the photosynthetic machinery (Jiao et al., 2017; Kim et al., 2018; Li Y. T. et al., 2018) or ROS production (Wang et al., 2015; Ali et al., 2016; Zhang et al., 2018; Xiao et al., 2019). It could therefore be concluded that BPA effects in plants are pleiotropic (Xiao et al., 2020). However, the increased demand for BPA and focus on BPA research over the past years (Shafei et al., 2018), has gathered significant amount of evidence indicating that the induction of ROS is the start of a cascade of BPA-induced cellular effects. As such, ROS contribute significantly to BPA toxic and carcinogenic potential (Moura et al., 2010). Specifically for plants, BPA effects on photosynthesis have been linked to ROS production (Li Y. T. et al., 2018), but fascinatingly a protective role for ROS in the plant response against BPA has been also proposed (Zhang et al., 2018), a phenomenon also observed in animal models (Guo et al., 2017; Durovcova et al., 2018) under BPA exposure.

It is evident that any change or imbalance in the function of the chloroplast will affect directly or/and indirectly the other cellular functions of the plant cell (Bobik and Burch-Smith, 2015). Earlier studies have suggested that the redox state of the plastoquinone (PQ) pool initiates plant acclimation and is of unique significance for antioxidant defense and signaling (Hüner et al., 2012). Consequently, it can be hypothesized that BPA stress in plants, like in animals (Moura et al., 2010), could be initially sensed via ROS-production; then the associated changes in the chloroplast oxidoreduction homeostasis synergistically with other signaling pathways could induce physiological or/ and molecular adaptive responses. In order to test this hypothesis and provide novel insights into mechanisms of BPA effects to plant physiological functions such as photosynthesis, we experimentally studied the effects of BPA aqueous solutions on several parameters of photosystem II (PSII) functionality in detached leaves of the model plant Arabidopsis thaliana. In particular, we investigated whether the BPA-induced hydrogen peroxide $\left(\mathrm{H}_{2} \mathrm{O}_{2}\right)$ in combination with the $\mathrm{H}_{2} \mathrm{O}_{2}$ scavenger, $\mathrm{N}$ acetylcysteine, has a positive or negative action on the selected photosynthetic parameters.

\section{MATERIALS AND METHODS}

\section{Plant Material and Growth Conditions}

Arabidopsis thaliana (L.) Heynh. (Col-0) seeds, obtained from Nottingham Arabidopsis Stock Centre (NASC), were bleach surface sterilized and after being imbibed at $4^{\circ} \mathrm{C}$ for $24 \mathrm{~h}$ were sown directly on soil. Emerged seedlings were left to grow at a $22 \pm 1{ }^{\circ} \mathrm{C}$ temperature and a $16-\mathrm{h} / 8-\mathrm{h}$ light/dark cycle at 120 $\mu \mathrm{mol}$ photons $\mathrm{m}^{-2} \mathrm{~s}^{-1}$ light intensity and $60 \pm 5 \%$ day/night humidity for 4 weeks. Rosette leaves 8 from 4 -week-old plants were cut and further on processed.

\section{BPA and NAC Treatments}

Detached leaves of $A$. thaliana maintained in Petri dishes on filter paper soaked with distilled water were considered as controls. Four to five leaves per experiment were treated with aqueous 50 and $100 \mathrm{mg} \mathrm{L}^{-1}(0.2$ and $0.4 \mathrm{mM})$ BPA solutions, prepared from a stock solution of $200 \mathrm{mg} \mathrm{L}^{-1}$ at $21.5^{\circ} \mathrm{C}, \mathrm{pH} 7.0$ (Staples et al., 1998; Adamakis et al., 2013; Adamakis et al., 2019), soaked on filter paper in Petri dishes, for 6, 12 and 24 h. Each treatment has been done in triplicate.

$\mathrm{N}$-acetylcysteine (NAC) is a ROS scavenger capable of interacting with $\mathrm{H}_{2} \mathrm{O}_{2}$ (Aruoma et al., 1989; Zafarullah et al., 2003; Ezeringa et al., 2018). We applied NAC on detached A. 
thaliana leaves to evaluate the result of $\mathrm{H}_{2} \mathrm{O}_{2}$ scavenging in combination with BPA action. Leaves were treated with either $500 \mu$ M NAC (Muranaka et al., 2013; Livanos et al., 2016; Colak et al., 2019) or with $50 \mathrm{mg} \mathrm{L}^{-1}(0.2 \mathrm{mM}) \mathrm{BPA}$ plus $500 \mu \mathrm{M}$ NAC or with $50 \mathrm{mg} \mathrm{L}^{-1} \mathrm{BPA}$ alone for $24 \mathrm{~h}$. All treatments were performed with three independent biological replicates.

\section{Hydrogen Peroxide Imaging Detection}

$\mathrm{H}_{2} \mathrm{O}_{2}$ detection in $A$. thaliana leaves was implemented as described earlier (Moustaka et al., 2015). Briefly, leaves were incubated for $30 \mathrm{~min}$ with $25 \mu \mathrm{M} \mathrm{2}$, $7^{\prime}$-dichlorofluorescein diacetate $\left(\mathrm{H}_{2} \mathrm{DCF}-\mathrm{DA}\right.$, Sigma) in $10 \mathrm{mM}$ Tris- $\mathrm{HCl}(\mathrm{pH} 7.4)$ in dark. The leaves were observed under a Zeiss AxioImager.Z2 fluorescence microscope at excitation and emission wavelengths of 480 and $530 \mathrm{~nm}$, respectively (Moustaka et al., 2015). An AxioCam MRc 5 camera attached to the microscope captured the images. Autofluorescence signal interference was also checked (Moustaka et al., 2018). All treatments were performed with three independent biological replicates.

\section{Chlorophyll Fluorescence Imaging Analysis}

A modulated chlorophyll fluorescence system (Imaging PAM MSeries system, Heinz Walz Instruments, Effeltrich, Germany) was used to evaluate the spatiotemporal effects of BPA on PSII photochemistry. Chlorophyll fluorescence in dark-adapted (for $20 \mathrm{~min}$ ) detached $A$. thaliana leaves was measured at room temperature as described previously (Moustaka et al., 2015). Two light intensities were used for chlorophyll fluorescence measurements, a low light intensity $\left(140 \mu \mathrm{mol}\right.$ photons $\mathrm{m}^{-2}$ $\mathrm{s}^{-1}$ ) that was similar to the growth light and a high light intensity $\left(1000 \mu \mathrm{mol}\right.$ photons $\left.\mathrm{m}^{-2} \mathrm{~s}^{-1}\right)$. Color-coded images are presented of dark adapted leaves of (a) the maximum photochemical efficiency $(\mathrm{F} v / \mathrm{Fm})$, and after $5 \mathrm{~min}$ of illumination, (b) the effective quantum yield of PSII photochemistry $\left(\Phi_{\text {PSII }}\right)$ that estimates the efficiency by which light absorbed by PSII is used for photochemistry, (c) the quantum yield of regulated nonphotochemical energy loss in PSII $\left(\Phi_{\mathrm{NPQ}}\right)$, (d) the quantum yield of non-regulated energy loss in PSII $\left(\Phi_{\mathrm{NO}}\right)$, and (e) the photochemical quenching $\left(\mathrm{q}_{\mathrm{p}}\right)$, a measure of the fraction of open PSII reaction centers, that is the redox state of the plastoquinone (PQ) pool. Nine to fourteen areas of interest (AOIs) were selected in each leaf so as to have representative areas of the whole leaf.

\section{Statistical Analyses}

Statistically significant differences were evaluated for the chlorophyll fluorescence parameters of Control Whole Leaves (CWL), BPA treated Whole Leaves (BWL), Spot BPA zone (SPB), Spot Surrounding Area (SSA) and the Rest of the Leaf $(\mathrm{RL})$, that is the leaf area that remains if the Spot BPA zone (SPB) and the Spot Surrounding Area (SSA) are subtracted from the BPA-treated Whole Leaves (BWL). The measured chlorophyll fluorescence parameters were analyzed by t-test at a level of $\mathrm{P}<$ 0.05 (StatView computer package, Abacus Concepts, Inc Berkley, CA, USA). Data are presented as means from three independent experiments.

\section{RESULTS}

We evaluated the effects of 50 and $100 \mathrm{mg} \mathrm{L}^{-1} \mathrm{BPA}$ treatments for 6, 12 and $24 \mathrm{~h}$ on the chlorophyll fluorescence parameters $\mathrm{F} v /$ F $m, \Phi_{\mathrm{PSII}}, \Phi_{\mathrm{NPQ}}, \Phi_{\mathrm{NO}}$, and $\mathrm{q}_{\mathrm{p}}$ in order to evaluate BPA effects on PSII functionality. Color-coded images after $20 \mathrm{~min}$ dark adaptation of $\mathrm{F} v / \mathrm{Fm}$, and after 5 min illumination $(140 \mu \mathrm{mol}$ photons $\mathrm{m}^{-2} \mathrm{~s}^{-1}$ ) for $\Phi_{\mathrm{PSII}}, \Phi_{\mathrm{NPQ}}, \Phi_{\mathrm{NO}}$, and $\mathrm{q}_{\mathrm{p}}$, of either control (leaves maintained in Petri dishes on soaked filter paper with distilled water) or of BPA treated leaves (maintained in Petri dishes on soaked filter paper with 50 and $100 \mathrm{mg} \mathrm{L}^{-1}$ aqueous BPA solution) for $6 \mathrm{~h}$ are presented in Figure 1. We observed a spot-like mode of action of BPA after $6 \mathrm{~h}$ treatment with $100 \mathrm{mg}$ $\mathrm{L}^{-1}$ that could not be observed after $6 \mathrm{~h}$ treatment with $50 \mathrm{mg} \mathrm{L}^{-1}$ (Figure 1). However, the spot-like mode of BPA action was visible after 12 and $24 \mathrm{~h}$ treatment with $50 \mathrm{mg} \mathrm{L}^{-1}$ under both low light (Figure 2) and high light (Figure 3) intensities.

After $6 \mathrm{~h}$ treatment with $50 \mathrm{mg} \mathrm{L}^{-1}$ BPA $\Phi_{\text {PSII }}$ values of the mid vein AOIs (arrows) increased compared to their corresponding controls, while $\Phi_{\mathrm{NO}}$ values of the mid vein AOIs decreased compared to their corresponding controls (Figure 1). In addition, the fraction of open PSII reaction centers $\left(q_{p}\right)$ of the mid vein AOIs (arrows) increased, compared to their corresponding controls (Figure 1). After $6 \mathrm{~h}$ treatment with $100 \mathrm{mg} \mathrm{L}^{-1} \mathrm{BPA}$, the same pattern as $50 \mathrm{mg}$ $\mathrm{L}^{-1}$ BPA treatment was observed for $\Phi_{\mathrm{PSII}}$ and $\Phi_{\mathrm{NO}}$ values but only for the lower mid vein AOI, while $q_{p}$ values increased for both the mid vein AOIs (arrows) (Figure 1). This treatment (100 $\mathrm{mg} \mathrm{L}^{-1} \mathrm{BPA}, 6 \mathrm{~h}$ ) decreased significantly $\mathrm{F} v / \mathrm{Fm}$ value of the whole leaf and mid vein AOIs (arrows) compared to the control values (Figure 1).

Under 12 and $24 \mathrm{~h}$ treatments with $50 \mathrm{mg} \mathrm{L}^{-1} \mathrm{BPA}$ the fraction of open PSII reaction centers $\left(q_{p}\right)$ of the whole leaf increased (with the exception of the spot like affected AOI) compared to control (Figure 2). Exposure to high light (1000 $\mu \mathrm{mol}$ photons $\mathrm{m}^{-2} \mathrm{~s}^{-1}$ ) of Arabidopsis leaves resulted in increased leaf heterogeneity under non-stressed conditions of the chlorophyll fluorescence parameters $\Phi_{\mathrm{PSII}}, \Phi_{\mathrm{NPQ}}$, and $\mathrm{q}_{\mathrm{p}}$ as was evidenced from the whole leaf color-coded images and the increased standard deviation (Figure 3). After $12 \mathrm{~h}$ treatment with $50 \mathrm{mg} \mathrm{L}^{-1} \mathrm{BPA}$, whole leaf $\Phi_{\mathrm{PSII}}$ value under high light decreased significantly, with the spot like affected AOI to have

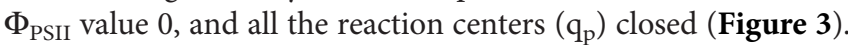

The effects of BPA treatment on the allocation of the absorbed light energy in $A$. thaliana leaves are presented in Figure 4. We estimated the fraction of the absorbed light energy that is used for photochemistry $\left(\Phi_{P S I I}\right)$ (Figures $\left.4 \mathbf{A}-\mathbf{C}\right)$, the fraction that is lost by regulated heat dissipation $\left(\Phi_{N P Q}\right)$ (Figures $\left.4 \mathbf{D}-\mathbf{F}\right)$, and the fraction of non-regulated energy loss $\left(\Phi_{N O}\right)$ (Figures 4G-I). These three quantum yields $\left(\Phi_{P S I}, \Phi_{N P Q}\right.$, and $\left.\Phi_{N O}\right)$ add up to unity. After $6 \mathrm{~h}$ treatment with $50 \mathrm{mg} \mathrm{L}^{-1}, \Phi_{\text {PSII }}$ values of BPAtreated whole leaves (BWL) increased $6 \%$ compared to control (CWL), without any significant difference at the BPA zone (SPB) and the surrounding area (SSA) compared to CWL, but with a significant increased (7\%) value at the rest of the leaf (RL) (Figure 4A). After 12 and $24 \mathrm{~h}$ treatment, $\Phi_{\text {PSII }}$ values at the spot BPA zone (SPB) decreased (64\% and $86 \%$ respectively), 

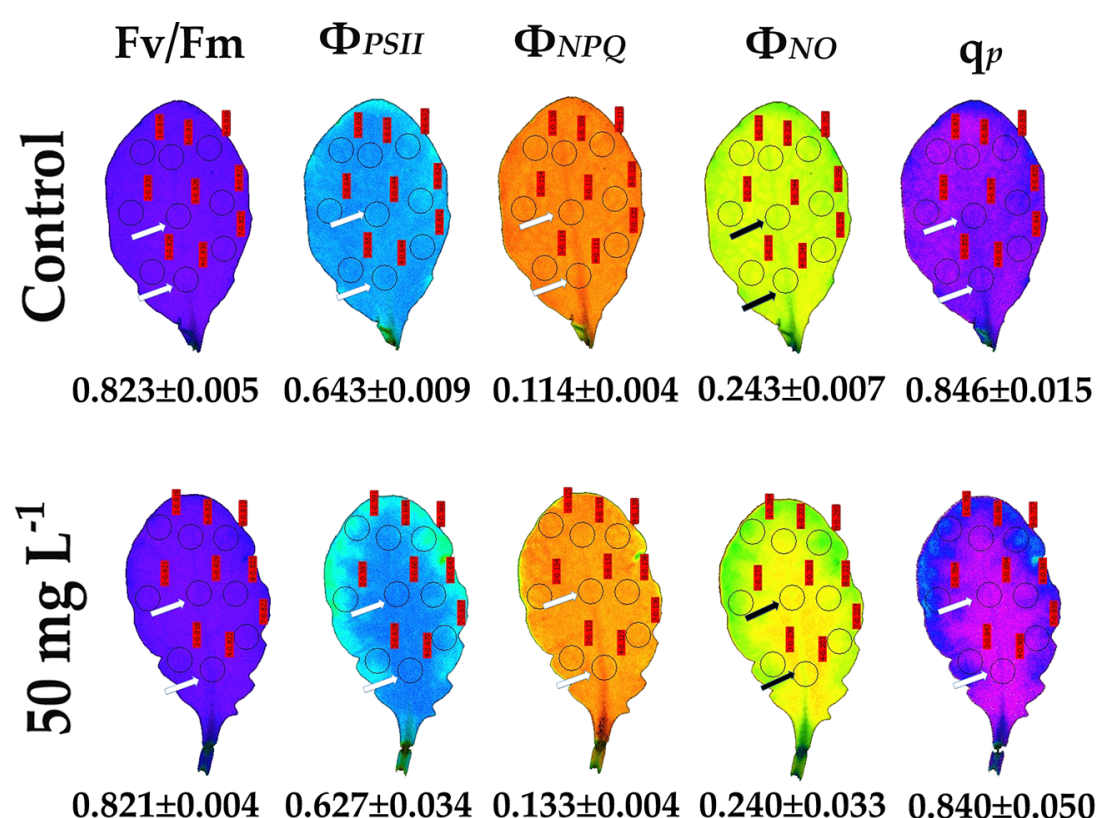

$0.133 \pm 0.0040 .240 \pm 0.033$

$0.840 \pm 0.050$
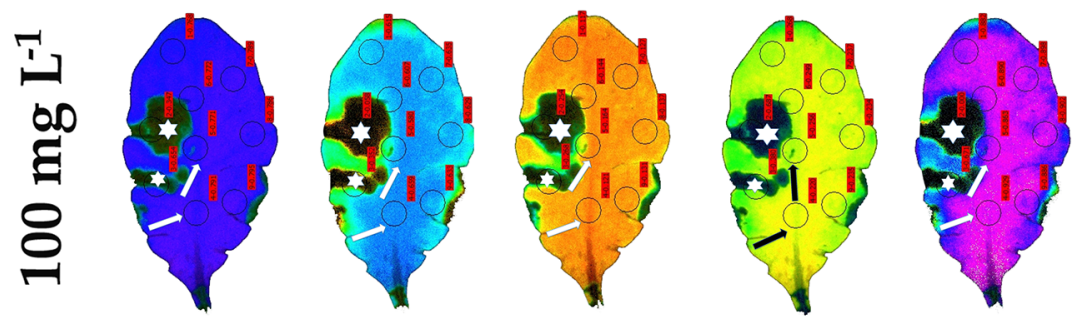

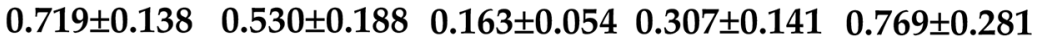

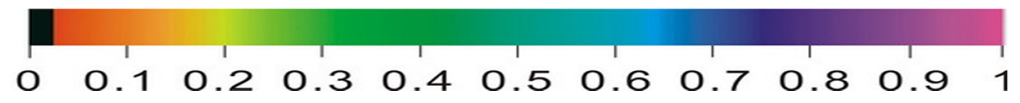

FIGURE 1 | Color-coded images of the chlorophyll fluorescence parameters Fv/Fm acquired after dark adaptation, and of $\Phi_{P S I l}, \Phi_{N P Q}, \Phi_{N O}$, and $q_{P}$, acquired with $140 \mu \mathrm{mol}$ photons $\mathrm{m}^{-2} \mathrm{~s}^{-1}$ light intensity, after exposure to 0 (control), 50 and $100 \mathrm{mg} \mathrm{L}^{-1}$ BPA for $6 \mathrm{~h}$. The color code depicted at the bottom of the images ranges from black (pixel values 0.0) to purple (1.0). Nine areas of interest (AOls) are shown in each image together with the average value ( \pm SD) of the whole leaf for each photosynthetic parameter. Arrows in the images point at the mid vein AOls that were not affected or affected (negatively or positively) by the BPA application. Asterisks on the images note the AOls that were negatively affected by the BPA application.

while at the rest of the leaf (RL) increased (7\% and 5\% respectively) compared to CWL (Figures 4B, C, respectively). $\Phi_{\mathrm{NPQ}}$ values did not change after $6 \mathrm{~h}$ treatment with $50 \mathrm{mg} \mathrm{L}^{-1}$ $\mathrm{BPA}$ at all evaluated zones (Figure 4D), but increased significantly (114\%) at the SPB after $12 \mathrm{~h}$ treatment (Figure $\mathbf{4 E}$ ), while decreased significantly $(21 \%)$ at the same zone after $24 \mathrm{~h}$ treatment compared to CWL (Figure $4 \mathbf{F}$ ). $\Phi_{\text {NO }}$ values did not change after $6 \mathrm{~h}$ treatment with $50 \mathrm{mg} \mathrm{L}^{-1}$ at the spot BPA zone (SPB) compared to CWL (Figure 4G), but after 12 and $24 \mathrm{~h}$ treatment increased significantly (66\% and $173 \%$ respectively) at the same zone compared to CWL (Figures $\mathbf{4 H}$, I, respectively). At the rest of the leaf (RL) after $12 \mathrm{~h}$ treatment $\Phi_{\mathrm{NO}}$ decreased (8\%) (Figure $\mathbf{4 H}$ ), while after $24 \mathrm{~h}$ treatment remained unchanged (Figure 4I) compared to CWL.
The maximum photochemical efficiency $(\mathrm{F} v / \mathrm{Fm})$ was the only chlorophyll fluorescence parameter that was negatively affected in a dose- and time-dependent manner in the BPAtreated whole leaves (BWL) and not only at the spot BPA zone (SPB) (Figures 5A-C), as was observed at the other measured parameters (Figure 4). The redox state of the plastoquinone (PQ) pool $\left(q_{p}\right)$, a measure of the fraction of open PSII reaction centers, increased after 6,12 and $24 \mathrm{~h}$ treatment in BPA-treated whole leaves (BWL) and the rest of the leaf (RL) (Figures 5D-F).

Exposure of $A$. thaliana leaves to $50 \mathrm{mg} \mathrm{L}^{-1} \mathrm{BPA}$ plus $500 \mu \mathrm{M}$ NAC for 24 h eliminated whole leaf $\Phi_{\mathrm{PSI}}$ and $\Phi_{\mathrm{NPQ}}$ having as a consequence only $\Phi_{\mathrm{NO}}$ to occur, and all the reaction centers to be closed (Figure 6). Exposure of leaves to $500 \mu \mathrm{M}$ NAC alone for $24 \mathrm{~h}$ resulted in milder effects on chlorophyll fluorescence 

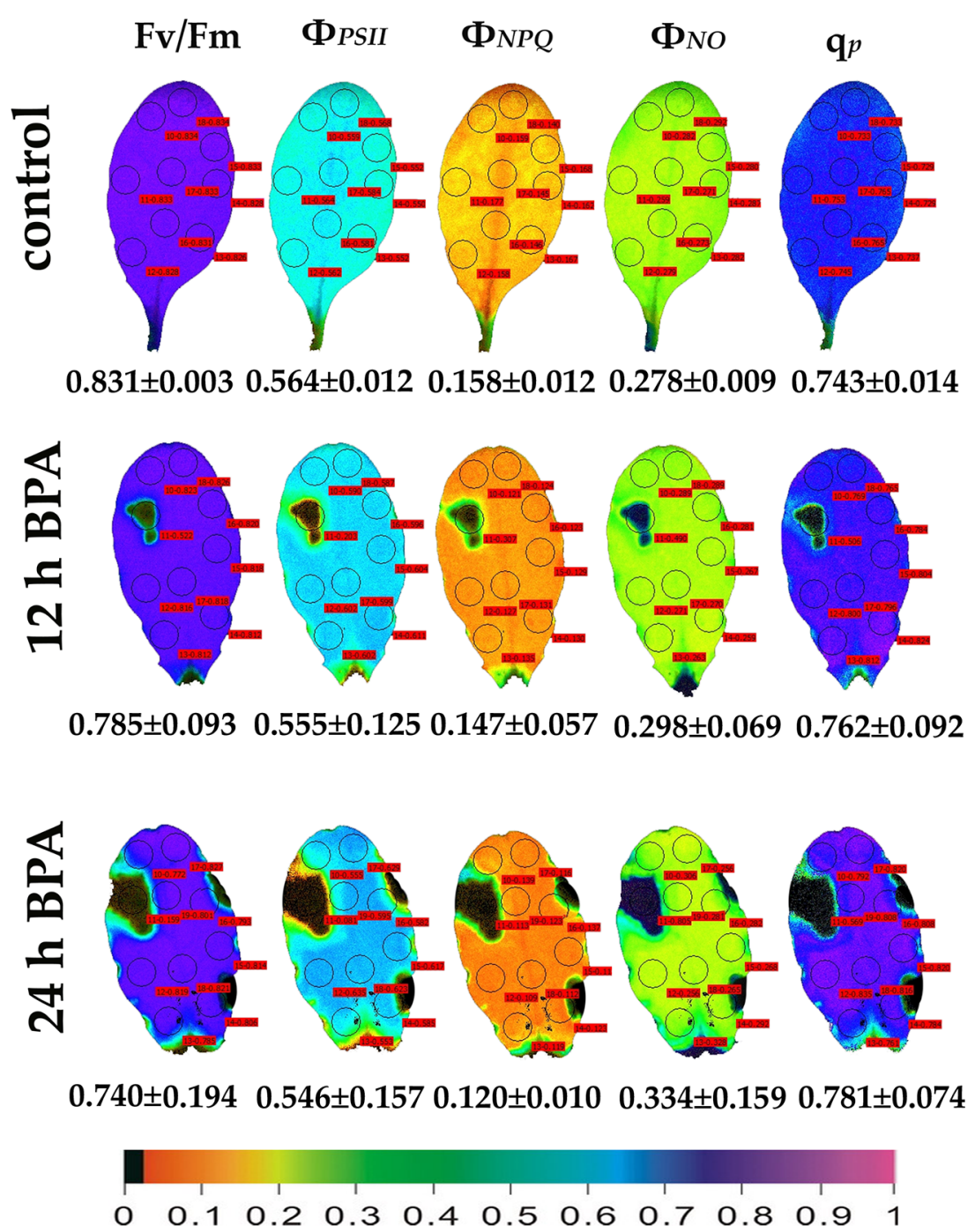

FIGURE 2 | Color-coded images of the chlorophyll fluorescence parameters Fv/Fm acquired after dark adaptation and of $\Phi_{P S I l}, \Phi_{N P Q}$, $\Phi_{N O}$, and $q_{\mathrm{P}}$, acquired with $140 \mu \mathrm{mol}$ photons $\mathrm{m}^{-2} \mathrm{~s}^{-1}$ light intensity, after exposure to 0 (control) and $50 \mathrm{mg} \mathrm{L}^{-1}$ BPA for 12 and $24 \mathrm{~h}$. The color code depicted at the bottom of the images ranges from black (pixel values 0.0 ) to purple (1.0). Nine or ten AOls are shown in each image together with the average value ( \pm SD) of the whole leaf for each photosynthetic parameter.

parameters (Figure 6). However, a $68 \%$ reduction of the maximum photochemical efficiency $(\mathrm{F} v / \mathrm{Fm})$, a $78 \%$ reduction in the absorbed PSII light that is used for photochemistry $\left(\Phi_{\text {PSII }}\right)$ and a $62 \%$ reduction in the photoprotective energy dissipation as heat $\left(\Phi_{\mathrm{NPQ}}\right)$ occurred. As a result, a 2.8 -fold increase in the quantum yield of non-regulated energy loss in PSII $\left(\Phi_{\mathrm{NO}}\right)$ occurred and a $64 \%$ reduction in the fraction of open PSII reaction centers $\left(q_{p}\right)$ (Figure 6). Twenty-four h treatment with $50 \mathrm{mg} \mathrm{L}^{-1}$ BPA alone had milder effects on chlorophyll fluorescence parameters from all the treatments (Figure 6).

Leaf spot BPA areas, negatively affected by BPA (asterisks in Figure 1 and Figures 2, 3, 6), showed highly increased chlorophyll fluorescence heterogeneity compared to the rest leaf, with a reduced fraction of open PSII reaction centers $\left(q_{p}\right)$ and an increased non-regulated energy loss $\left(\Phi_{\mathrm{NO}}\right)$. In those areas chlorophyll autofluorescence loss coexisted with an increased $\mathrm{H}_{2} \mathrm{O}_{2}$ production as was shown after $\mathrm{H}_{2}$ DCFDA staining (Figures 7D-I), a phenomenon not present in control leaves stained with $\mathrm{H}_{2}$ DCFDA (Figures 7A-C).

\section{DISCUSSION}

ROS production (especially $\mathrm{H}_{2} \mathrm{O}_{2}$ ) stimulated by BPA has been linked with the PSII photoinhibition observed under BPA treatments (Qui et al., 2013; Li Y. T. et al., 2018). BPA seems to affect the electron transport between PSII and PSI (Qiu et al., 2013), but it does not exert a direct PSII damage (Li Y. T. et al., 2018), since the block of ETR by BPA under high light is attributed to $\mathrm{CO}_{2}$ fixation inhibition (Li Y. T. et al., 2018). 

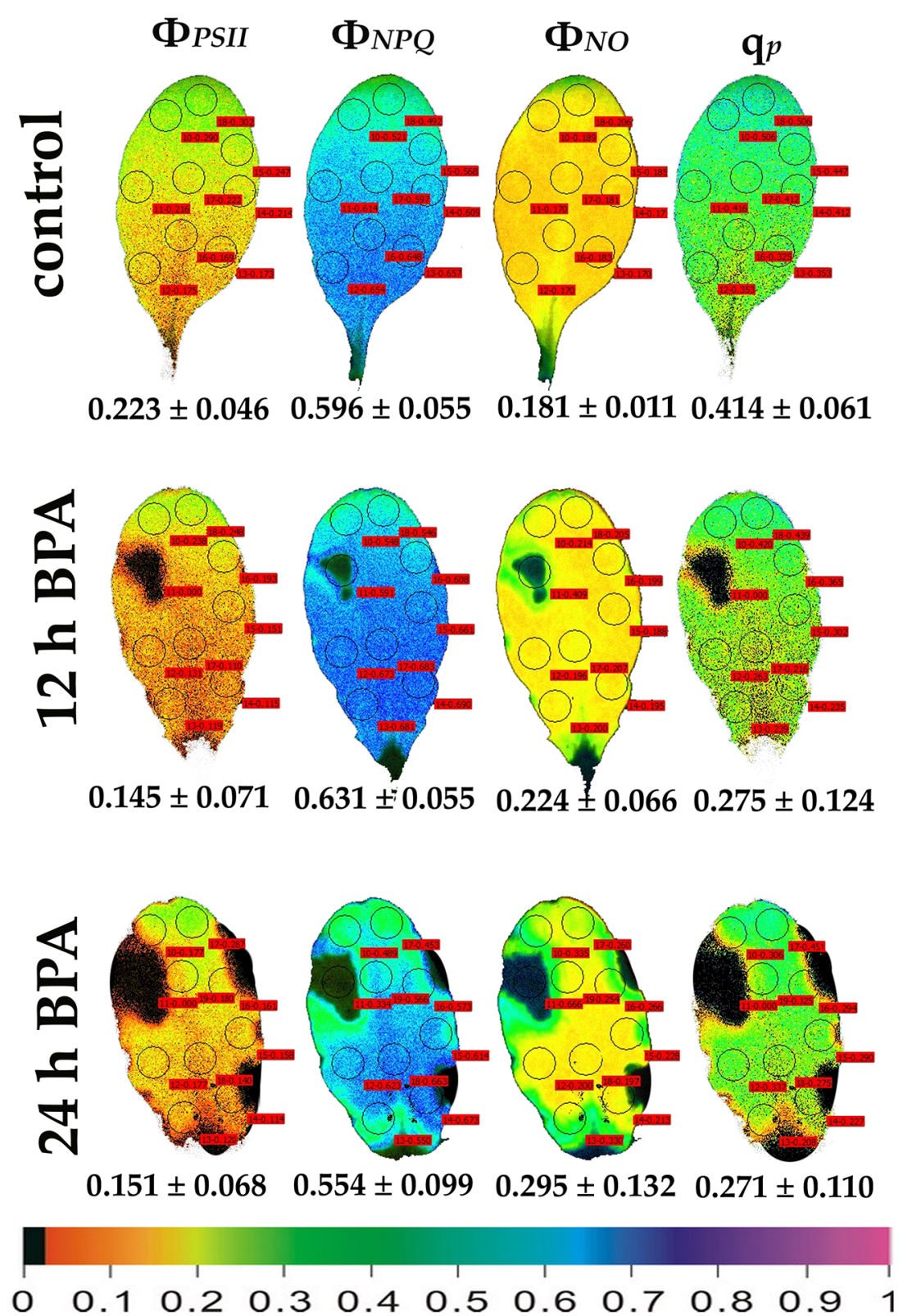

FIGURE 3 | Color-coded images of the chlorophyll fluorescence parameters $\Phi_{P S I I}, \Phi_{N P Q}, \Phi_{N O}$, and $q_{P}$, acquired with $1000 \mu$ mol photons $\mathrm{m}^{-2} \mathrm{~s}^{-1}$ light intensity, after exposure to 0 (control) and $50 \mathrm{mg} \mathrm{L}^{-1}$ BPA for 12 and $24 \mathrm{~h}$. The color code depicted at the bottom of the images ranges from black (pixel values 0.0 ) to purple (1.0). Nine or ten AOls are shown in each image together with the average value $( \pm \mathrm{SD})$ of the whole leaf for each photosynthetic parameter.

Moreover, in soybean BPA-treated seedlings, the inhibition of growth was related to the decrease in photosynthesis due to a decrease in the content of chlorophyll, the net photosynthetic rate and changes in the chlorophyll fluorescence parameters $\mathrm{F} v /$ $\mathrm{F} m, \Phi_{\mathrm{PSII}}$, and ETR that were decreased, compared to the control (Qiu et al., 2013). In the present study, under low light, PSII function was negatively influenced only at the spot affected BPA zone in a dose- and time-dependent manner, while at the whole leaf only the maximum photochemical efficiency $(\mathrm{F} v / \mathrm{Fm})$ was negatively affected (Figures 4, 5). This BPA induced decrease in
$\mathrm{F} v / \mathrm{Fm}$ suggests photoinhibition of PSII caused by ROS through inhibition of $\mathrm{CO}_{2}$ assimilation and over-reduction of ETR that increased $\mathrm{ROS}\left(\mathrm{H}_{2} \mathrm{O}_{2}\right)$ generation inhibiting the repair of photodamaged PSII (Li Y. T. et al., 2018). In our experiments, under high light all PSII photosynthetic parameters $\left(\Phi_{P S I}, \Phi_{N P Q}\right.$, $\Phi_{N O}$, and $q_{\mathrm{P}}$ ) were negatively affected by BPA application, in a time-dependent manner (Figure 3), also in detached leaves directly exposed to BPA aqueous solutions. Increased BPA concentration ( $100 \mathrm{mg} \mathrm{L}^{-1} \mathrm{BPA}, 6 \mathrm{~h}$ exposure $q_{\mathrm{P}}$ image, Figure 1) or high light exposure (50 $\mathrm{mg} \mathrm{L}^{-1} \mathrm{BPA}, 12$ and $24 \mathrm{~h}$ exposure 

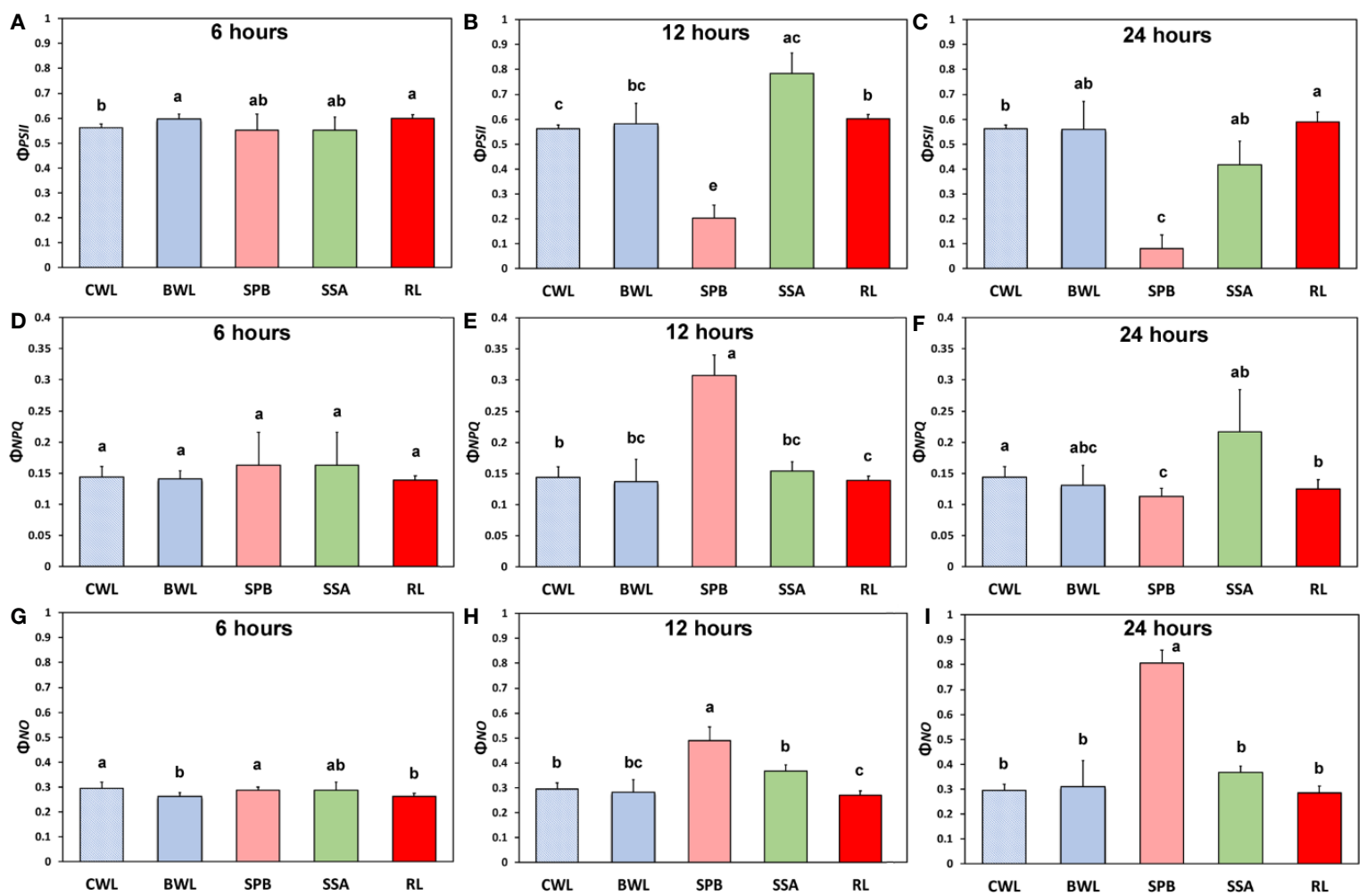

FIGURE 4 | The effects of $50 \mathrm{mg} \mathrm{L}^{-1}$ BPA on the effective quantum yield of photochemical energy conversion in PSII ( $\left.\Phi_{P S I I}\right)$ after 6-h (A), 12-h (B), and 24-h exposures (C); the quantum yield of regulated non-photochemical energy loss in PSII ( $\left.\Phi_{N P Q}\right)$ after 6 h (D), $12 \mathbf{h}$ (E) and $24 \mathbf{h}$ exposure (F); and the quantum yield of

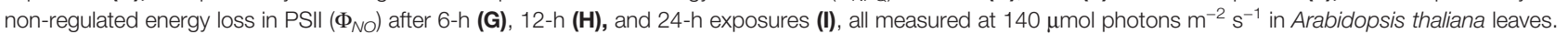
Symbol explanation: Control Whole Leaves (CWL) maintained in Petri dishes on filter paper soaked with distilled water and considered as controls; BPA treated whole leaves (BWL) maintained in Petri dishes on filter paper soaked with $50 \mathrm{mg} \mathrm{L}^{-1}$ BPA; spot BPA zone (SPB) the spot like zone that was affected by BPA; spot surrounding area (SSA); Rest of the Leaf (RL), that is the leaf area that remains if the Spot BPA zone (SPB) and the spot surrounding area (SSA) are subtracted from the BPA-treated Whole Leaves (BWL). Error bars on columns are standard deviations based on three independent biological replicates under all treatments.

Columns under the same time treatment with the same letter are statistically not different $(P<0.05)$.

$q_{\mathrm{P}}$ images, Figure 3) resulted to necrotic death-like spots in leaves, probably caused by increased $\mathrm{H}_{2} \mathrm{O}_{2}$ accumulation visible in a spot-like manner (Figure 7).

Using the $\mathrm{H}_{2}$ DCFDA staining we observed an increased $\mathrm{H}_{2} \mathrm{O}_{2}$ accumulation, in spots in the leaf periphery (Figure 7) under BPA treatments. BPA-induced $\mathrm{H}_{2} \mathrm{O}_{2}$, could be a toxic ROS able to cause damage to a variety of cellular structures but in parallel can act as a potent signaling molecule involved in BPA stress response, as it has been demonstrated in a plethora of physiological functions (Foyer and Shigeoka, 2011; Petrov and Breusegem, 2012; Foyer and Noctor, 2013; Moustaka et al., 2015; Moustakas et al., 2016). $\mathrm{H}_{2} \mathrm{O}_{2}$ enters the cell through aquaporins and regulates physiological and cellular processes (Foyer, 2020; Wu et al., 2020). Still, $\mathrm{H}_{2} \mathrm{O}_{2}$ can diffuse through leaf veins to act as a long-distance regulator molecule activating the antioxidant defense during stress in plants (Wilson et al., 2006; Mittler et al., 2011; Petrov and Breusegem, 2012; Moustaka et al., 2015; Moustakas et al., 2017; Antonoglou et al., 2018; Sperdouli et al., 2019). Since $\mathrm{H}_{2} \mathrm{O}_{2}$ travels through veins faster than from cell to cell, it seems logic why at $6 \mathrm{~h}$ treatments with 50 and 100 $\mathrm{mg} \mathrm{L}^{-1}$ BPA the fraction of open PSII reaction centers $\left(q_{p}\right)$ of the mid veins AOIs (arrows) were those areas that increased first, compared to their corresponding controls (Figure 1), while just at longer treatments (12 and $24 \mathrm{~h}$ with $50 \mathrm{mg} \mathrm{L}^{-1} \mathrm{BPA}$ ) whole leaf $\mathrm{q}_{p}$ values increased (with the exception of the spot like affected AOIs) compared to controls (Figure 2). However, the exposure of $A$. thaliana leaves to high light and $50 \mathrm{mg} \mathrm{L}^{-1} \mathrm{BPA}$ (12 and $24 \mathrm{~h}$ treatment) (Figure 3 ) decreased the effective quantum yield of PSII ( $\left.\Phi_{\text {PSII }}\right)$ and over-reduced the redox state of PQ pool closing a fraction of open PSII reaction centers $\left(q_{p}\right)$ (Murabakshina et al., 2010; Foyer and Shigeoka, 2011; MignoletSpuyt et al., 2016; Moustaka et al., 2018). In agreement to our results, Li et al. (2018b) have noticed that, under high light the BPA treatment changed similarly $\Phi_{\mathrm{PSII}}$ and $\mathrm{q}_{\mathrm{p}}$, and concluded that the decrease in $\Phi_{\text {PSII }}$ was mainly due to the decline in $\mathrm{q}_{\mathrm{p}}$ rather than to the decrease in the efficiency of open PSII centers to utilize the absorbed light $(\mathrm{F} v / \mathrm{Fm})$.

The spatiotemporal pattern of BPA effects on A. thaliana treated leaves points out to the differential defense response of each cell to BPA stress as it has been shown for other abiotic 

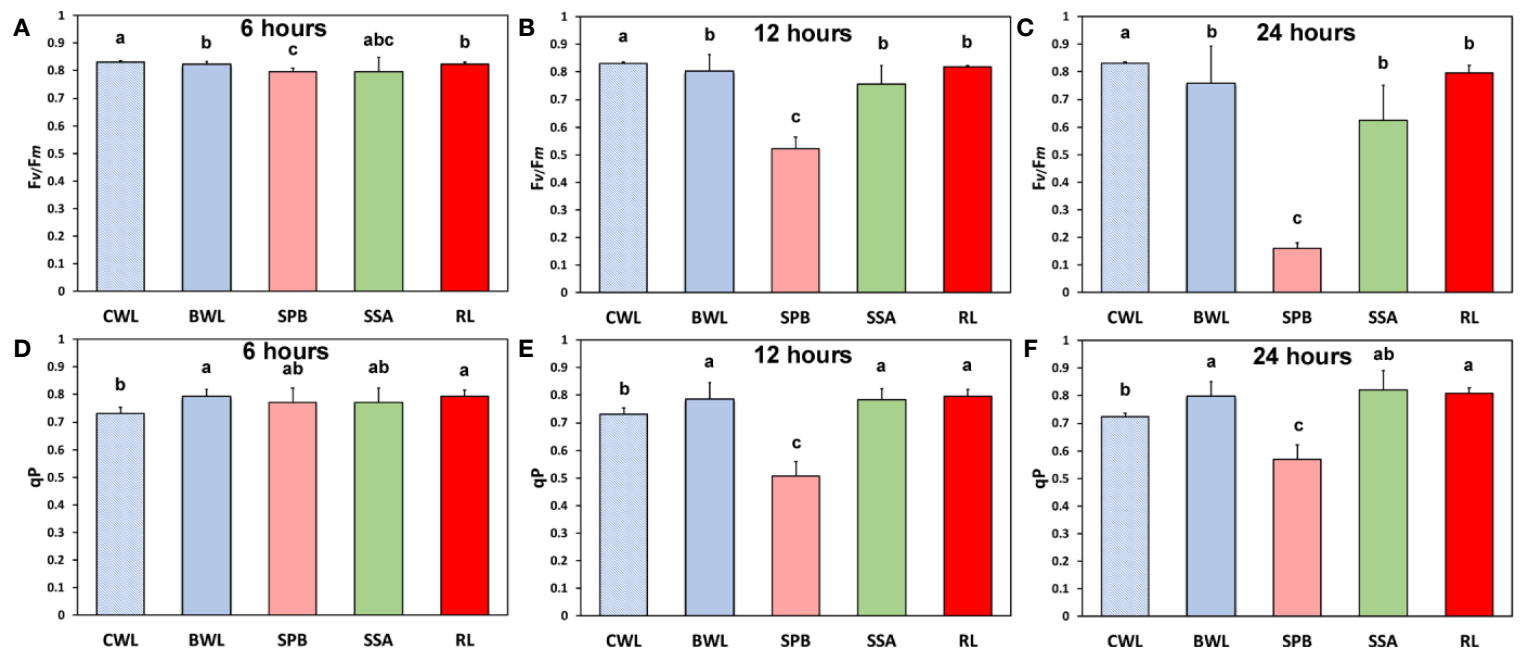

FIGURE 5 | The effects of $50 \mathrm{mg} \mathrm{L}^{-1}$ BPA on the maximum photochemical efficiency (Fv/Fm) after 6-h (A), 12-h (B), and 24-h exposure (C), and the redox state of the plastoquinone $(P Q)$ pool $\left(q_{p}\right)$, a measure of the fraction of open PSIl reaction centers after 6-h (D), 12-h (E), and 24-h exposures (F), all measured at $140 \mu$ mol photons $\mathrm{m}^{-2} \mathrm{~s}^{-1}$ in Arabidopsis thaliana leaves. Symbol explanation: control whole leaves (CWL) maintained in Petri dishes on filter paper soaked with distilled water and considered as controls; BPA-treated whole leaves (BWL) maintained in Petri dishes on filter paper soaked with $50 \mathrm{mg} \mathrm{L}^{-1}$ BPA; spot BPA zone (SPB) the spot like zone that was affected by BPA; spot surrounding area (SSA); rest of the leaf (RL), that is the leaf area that remains if the spot BPA zone (SPB) and the spot surrounding area (SSA) are subtracted from the BPA-treated whole leaves (BWL). Error bars on columns are standard deviations based on three independent biological replicates under all treatments. Columns under the same time treatment with the same letter are statistically not different $(P<0.05)$.

stress factors, e.g., drought (Sperdouli and Moustakas, 2012), hypoxia (Stasolla et al., 2019), paraquat (Moustakas et al., 2016), and heavy metals as Zn (Moustakas et al., 2019a), or Cd (Moustakas et al., 2019b). This can be due to the fact that plant cells have to defend themselves independently since they lack specialized cells and effective plant defense strongly relies in each single cell (Ruano and Scheuring, 2020).

In an earlier study, BPA residual concentrations had a negative correlation with $\mathrm{H}_{2} \mathrm{O}_{2}$ levels, i.e., an increase in $\mathrm{H}_{2} \mathrm{O}_{2}$ seemed to reduce BPA levels inside the plant tissue (Zhang et al., 2018). These results allowed to speculate that BPA could either be a direct target of ROS, and therefore subjected to oxidation (Reis et al., 2014) or ROS molecules could activate a cascade of secondary metabolic reactions degrading BPA (Noureddin et al., 2004) and finally the ROS-activated antioxidant enzymes could destroy BPA (Kang and Kondo, 2006). So in soybean roots, $\mathrm{H}_{2} \mathrm{O}_{2}$ initiated accumulation offered a protection against BPA (Zhang et al., 2018). Likewise, in our experimental system if BPAinduced $\mathrm{H}_{2} \mathrm{O}_{2}$ accumulation (Figure 7) is hindered, with NAC application (Figure 6), leaf photosynthesis is utterly being interrupted ( $\Phi_{\mathrm{NO}}=1$; Figure 6). Therefore, this $\mathrm{H}_{2} \mathrm{O}_{2}$ production could be necessary for promoting signaling events that could assist the plant to alleviate BPA-stress. NAC is a strong ROS scavenger (Zafarullah et al., 2003) since the SH group of NAC is able to donate an $\mathrm{H}$-atom or an electron. Numerous researchers have used it as a mean to reduce either the stress-induced or naturally occurring $\mathrm{H}_{2} \mathrm{O}_{2}$ (Livanos et al., 2012; Muranaka et al., 2013; Sun et al., 2014; Livanos et al., 2016; Adamakis and Eleftheriou, 2019; Colak et al., 2019). Generally, NAC is being considered not toxic for plants and the environment even when applied in high concentrations for large periods of time (i.e., Sun et al., 2014), able to alleviate oxidative stress induced by several stressors, e.g., heavy metals (Sun et al., 2014; Colak et al., 2019). However, when used to diminish naturally occurring ROS several cellular defects have been noticed. For instance, when NAC was applied in wheat or $A$. thaliana roots, microtubule organization was affected (Livanos et al., 2012) while cytokinesis failed to be accomplished (Livanos et al., 2016). The above indicated that ROS is an important factor enrolled in the microtubule assembly and cell division completion (Livanos et al., 2012; Livanos et al., 2016). Expanding the beneficial role of both naturally occurring and BPA-induced $\mathrm{H}_{2} \mathrm{O}_{2}$, we here noticed that ROS seem to have also pivotal role in the light reactions of photosynthesis. This comes as no surprise since the electron transport between PSII and PSI is a major source of ROS, which are considered more as signaling molecules rather than damaging ones (Hajiboland, 2014; Foyer et al., 2017). The role of chloroplast antioxidants, that often have overlying or interrelating functions, is not to totally eliminate $\mathrm{O}_{2}{ }^{-}, \mathrm{H}_{2} \mathrm{O}_{2}$ and ${ }^{1} \mathrm{O}_{2}$, but rather to achieve an appropriate balance between production and subtraction so that to match with the operation of photosynthesis and permit an efficient spread of signals to the nucleus (Foyer, 2018). When NAC diminished these naturally occurring ROS (Figure 6), all of the PSII photosynthetic parameters $\left(\Phi_{P S I}, \Phi_{N P Q}, \Phi_{N O}\right.$, and $\left.q_{\mathrm{p}}\right)$ were severely affected, indicating the importance of naturally occurring ROS in PSII photochemistry. Now it is well established that ROS are a necessary part of subcellular and intercellular communication in plants and that some of their signaling functions require ROS-metabolizing systems (Noctor et al., 2018). 


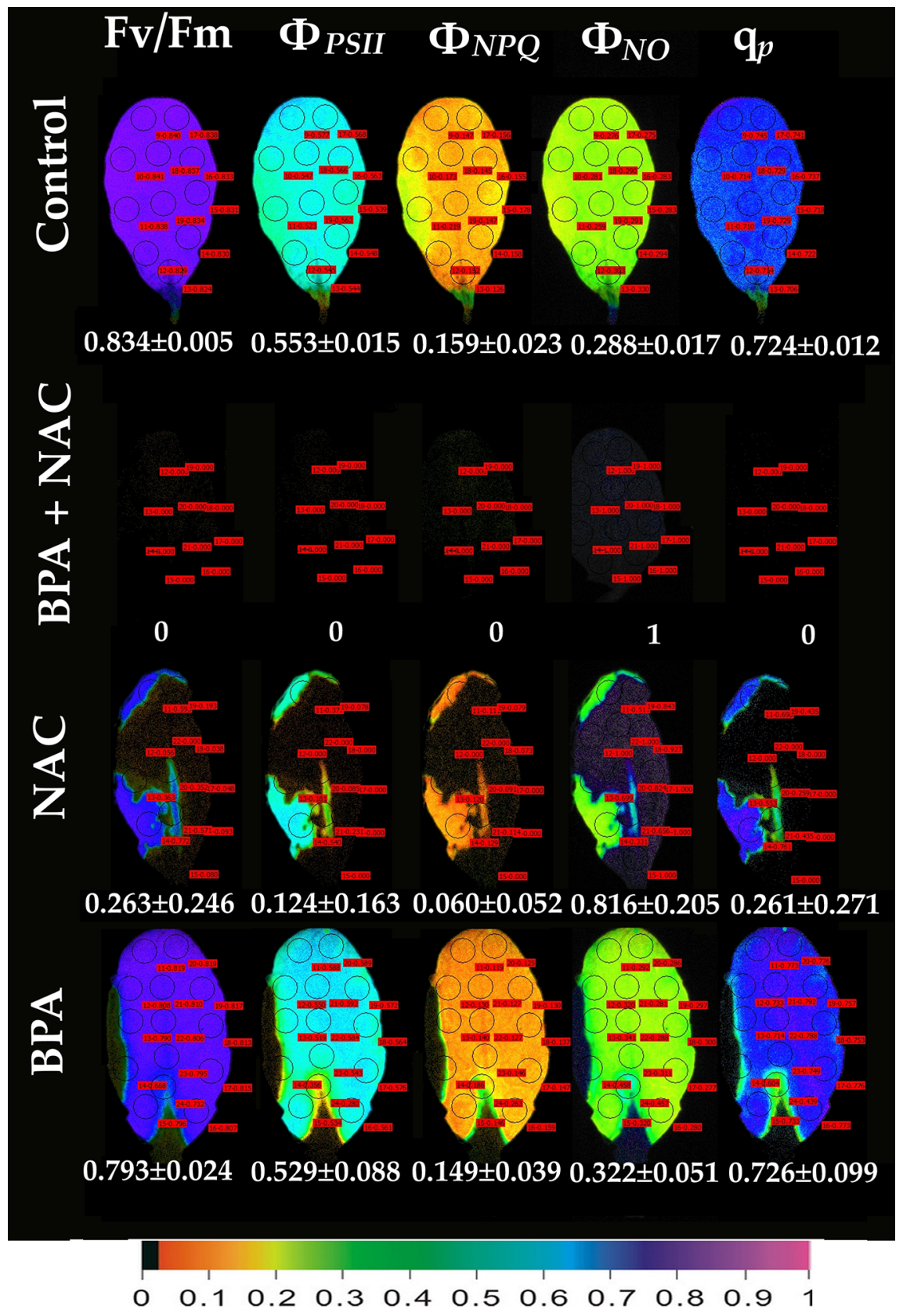

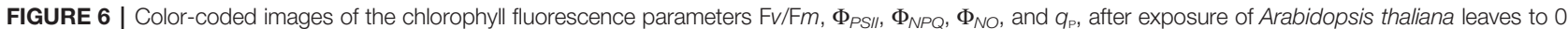
(control), or $50 \mathrm{mg} \mathrm{L}^{-1}$ BPA plus $500 \mu \mathrm{M}$ NAC, or $500 \mu \mathrm{M} \mathrm{NAC}$ alone, or only $50 \mathrm{mg} \mathrm{L}^{-1}$ BPA, for $24 \mathrm{~h}$. The color code depicted at the bottom of the images ranges from black (pixel values 0.0) to purple (1.0). Ten to fourteen AOls are shown in each image together with the average value $( \pm$ SD) of the whole leaf for each photosynthetic parameter.

Our results confirm the view that ROS-removing systems are considering ROS as beneficial molecules that regulate damaging ROS below dangerous levels (Noctor et al., 2018). So, one can easily conclude, that ROS seem to play a pivotal role in plant response against BPA toxicity (Zhang et al., 2018), as we observed in BPA-affected leaves of A. thaliana. While the concept that animal and plant cells need to remove ROS production to avoid extreme and permanent oxidation was the dominant view in the literature, the opinion is now shifting towards recognition of a positive role of ROS as well (Noctor and Foyer, 2016; Foyer et al., 2017). ROS generation can activate the plant's defense mechanisms in order to cope with the oxidative 

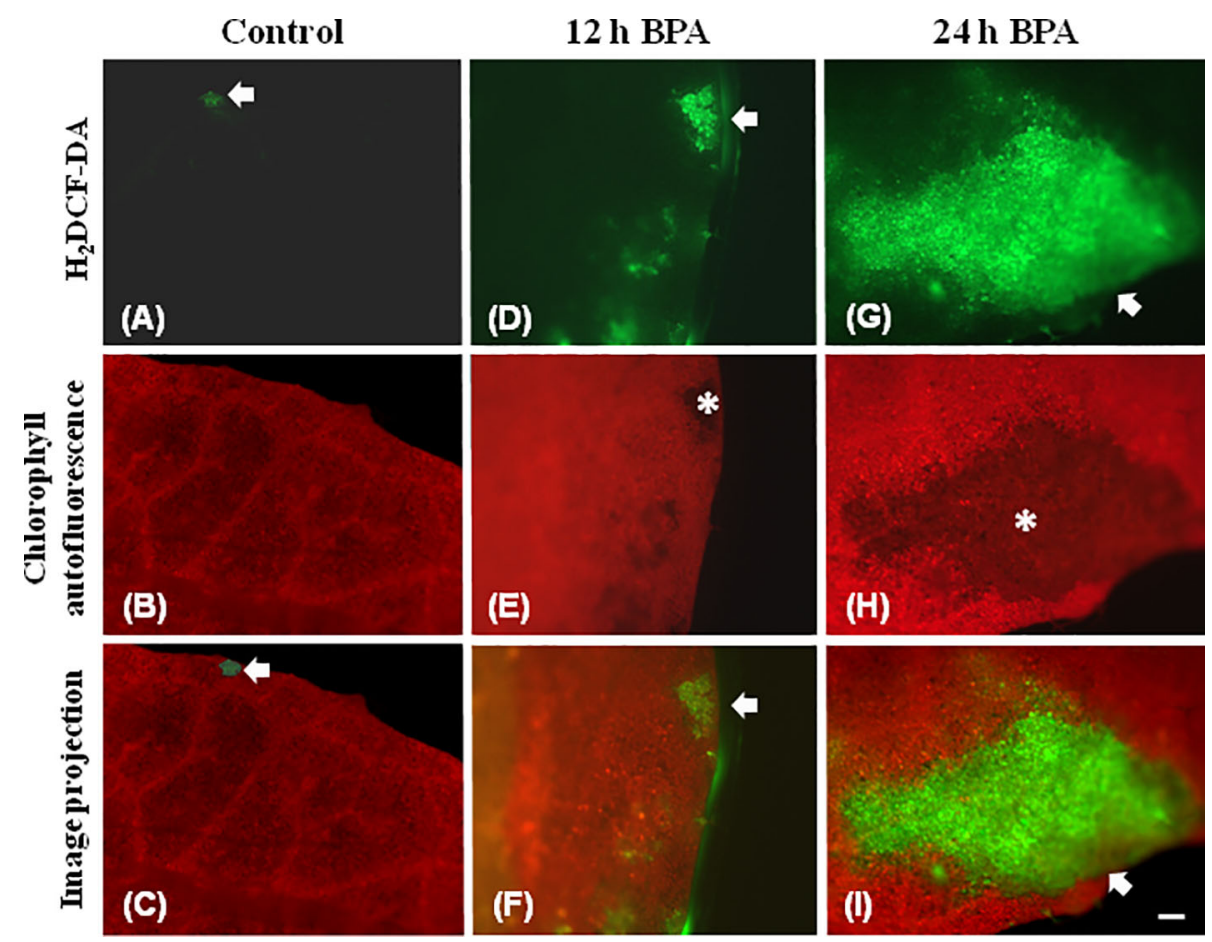

FIGURE 7 | Chlorophyll autofluorescence images (red) and after $\mathrm{H}_{2}$ DCF-DA staining, indicating $\mathrm{H}_{2} \mathrm{O}_{2}$ production (green) in untreated leaves (control) (A-C), $12 \mathrm{~h}$ (D-F), and $24 \mathrm{~h}$ (G-I) exposure to $50 \mathrm{mg} \mathrm{L}^{-1}$ BPA. In untreated leaves (A-C) very weak $\mathrm{H}_{2}$ DCF-DA staining was detected (A, C, arrows), while leaf margin areas exhibited strong chlorophyll autofluorescence (B). BPA-treated leaves exhibit reduced chlorophyll autofluorescence areas $(\mathbf{E}, \mathbf{H}$, asterisks) that coincide with timedependent increased production of $\mathrm{H}_{2} \mathrm{O}_{2}$ (arrows in D, F, G, I). Bar, $100 \mu \mathrm{m}$.

stress damage and are essential for redox sensing, signaling and regulation (Petrov et al., 2015; Foyer, 2018; Malea et al., 2019). Plants have developed during the course of evolution numerous ROS-generating pathways tightly accomplishing plant function and development (Noctor et al., 2018). Therefore, the necrotic death-like spots under BPA exposure could be due to ROS accumulation, but $\mathrm{H}_{2} \mathrm{O}_{2}$ production has dual function in plants playing also a protective role in BPA-induced stress. A crucial ROS role in the photochemical reactions of photosynthesis is further on confirmed.

\section{DATA AVAILABILITY STATEMENT}

All datasets presented in this study are included in the article/ supplementary material.

\section{REFERENCES}

Abraham, A., and Chakraborty, P. (2019). A review on sources and health impacts of bisphenol A. Rev. Environ. Health 35, 201-210. doi: 10.1515/reveh-20190034 eISSN 2191-0308, ISSN 0048-7554.

Adamakis, I.-D. S., and Eleftheriou, E. P. (2019). Structural evidence of programmed cell death induction by tungsten in root tip cells of Pisum sativum. Plants 8, 62. doi: 10.3390/plants8030062

Adamakis, I. D. S., Panteris, E., Cherianidou, A., and Eleftheriou, E. P. (2013). Effects of bisphenol A on the microtubule arrays in root meristematic cells of

\section{AUTHOR CONTRIBUTIONS}

I-DA and MM conceived and designed the experiments, I-DA and IS performed the experiments, I-DA, EE, and MM wrote the original draft of the manuscript. All authors contributed to the article and approved the submitted version.

\section{ACKNOWLEDGMENTS}

The authors would like to thank Emmanuel Panteris (Department of Botany, School of Biology, Aristotle University of Thessaloniki) for critical reading of the manuscript. The authors would also like to express our thanks to the reviewers whose constructive suggestions helped us to improve substantially our research work.

Pisum sativum L. Mutat. Res. Genet. Toxicol. Environ. Mutagen. 750, 111-120. doi: 10.1016/j.mrgentox.2012.10.012

Adamakis, I. D. S., Panteris, E., and Eleftheriou, E. P. (2016). Bisphenol A disrupts microtubules and induces multipolar spindles in dividing root tip cells of the gymnosperm Abies cephalonica. Chemosphere 149, 202-210. doi: 10.1016/j. chemosphere.2016.01.082

Adamakis, I.-D. S., Malea, P., and Panteris, E. (2018). The effects of Bisphenol A on the seagrass Cymodocea nodosa: Leaf elongation impairment and cytoskeleton disturbance. Ecotoxicol. Environ. Saf. 157, 431-440. doi: 10.1016/j.ecoenv. 2018.04.005 
Adamakis, I. D. S., Panteris, E., and Eleftheriou, E. P. (2019). Tubulin acetylation mediates bisphenol A effects on the microtubule arrays of Allium cepa and Triticum turgidum. Biomolecules 9, 1-15. doi: 10.3390/biom9050185

Ali, I., Liu, B., Farooq, M. A., Islam, F., Azizullah, A., Yu, C., et al. (2016). Toxicological effects of bisphenol A on growth and antioxidant defense system in Oryza sativa as revealed by ultrastructure analysis. Ecotoxicol. Environ. Saf. 124, 277-284. doi: 10.1016/j.ecoenv.2015.10.027

Ali, I., Jan, M., Wakeel, A., Azizullah, A., Liu, B., Islam, F., et al. (2017). Biochemical responses and ultrastructural changes in ethylene insensitive mutants of Arabidopsis thialiana subjected to bisphenol A exposure. Ecotoxicol. Environ. Saf. 144, 62-71. doi: 10.1016/j.ecoenv.2017.06.015

Antonoglou, O., Moustaka, J., Adamakis, I. D., Sperdouli, I., Pantazaki, A., Moustakas, M., et al. (2018). Nanobrass CuZn nanoparticles as foliar spray non phytotoxic fungicides. ACS Appl. Mater. Interf. 10, 4450-4461. doi: 10.1021/acsami.7b17017

Aruoma, O. I., Halliwell, B., Hoey, B. M., and Butler, J. (1989). The antioxidant action of $\mathrm{N}$-acetylcysteine: Its reaction with hydrogen peroxide, hydroxyl radical, superoxide, and hypochlorous acid. Free Radic. Biol. Med. 6, 593597. doi: 10.1016/0891-5849(89)90066-X

Awasthi, R., Bhandari, K., and Nayyar, H. (2015). Temperature stress and redox homeostasis in agricultural crops. Front. Environ. Sci. 3, 11. doi: 10.3389/ fenvs.2015.00011

Bahmani, R., Kim, D. G., Modareszadeh, M., Thompson, A. J., Park, J. H., Yoo, H. H., et al. (2020). The mechanism of root growth inhibition by the endocrine disruptor bisphenol A (BPA). Environ. Pollut. 257, 113516. doi: 10.1016/j.envpol. 2019.113516

Bobik, K., and Burch-Smith, T. M. (2015). Chloroplast signaling within, between and beyond cells. Front. Plant Sci. 6, 1-26. doi: 10.3389/fpls.2015.00781

Christou, A., Michael, C., Fatta-Kassinos, D., and Fotopoulos, V. (2018). Can the pharmaceutically active compounds released in agroecosystems be considered as emerging plant stressors? Environ. Int. 114, 360-364. doi: 10.1016/ j.envint.2018.03.003

Colak, N., Torun, H., Gruz, J., Strnad, M., and Ayaz, F. A. (2019). Exogenous NAcetylcysteine alleviates heavy metal stress by promoting phenolic acids to support antioxidant defence systems in wheat roots. Ecotoxicol. Environ. Saf. 181, 49-59. doi: 10.1016/j.ecoenv.2019.05.052

Durovcova, I., Spackova, J., Puskar, M., Galova, E., and Sevcovicova, A. (2018). Bisphenol A as an environmental pollutant with dual genotoxic and DNAprotective effects. Neuroendocrinol. Lett. 39 (4), 294-298.

Eleftheriou, E. P., Adamakis, I. D. S., Panteris, E., and Fatsiou, M. (2015). Chromium-induced ultrastructural changes and oxidative stress in roots of Arabidopsis thaliana. Int. J. Mol. Sci. 16, 15852-15871. doi: 10.3390/ ijms 160715852

Ezeriņa, D., Takano, Y., Hanaoka, K., Urano, Y., and Dick, T. P. (2018). N-acetyl cysteine functions as a fast-acting antioxidant by triggering intracellular $\mathrm{H}_{2} \mathrm{~S}$ and sulfane sulfur production. Cell Chem. Biol. 25, 447-459.e4. doi: 10.1016/ j.chembiol.2018.01.011

Foyer, C. H., and Noctor, G. (2013). Redox signaling in plants. Antioxid. Redox Signal. 18, 2087-2090. doi: 10.1089/ars.2013.5278

Foyer, C. H., and Shigeoka, S. (2011). Understanding oxidative stress and antioxidant functions to enhance photosynthesis. Plant Physiol. 155, 93-100. doi: $10.1104 / p p .110 .166181$

Foyer, C. H., Ruban, A. V., and Noctor, G. (2017). Viewing oxidative stress through the lens of oxidative signalling rather than damage. Biochem. J. 474, 877-883. doi: 10.1042/BCJ20160814

Foyer, C. H. (2018). Reactive oxygen species, oxidative signaling and the regulation of photosynthesis. Environ. Exp. Bot. 154, 134-142. doi: 10.1016/j.envexpbot. 2018.05.003

Foyer, C. H. (2020). Making sense of hydrogen peroxide signals. Nature 578, 518519. doi: 10.1038/d41586-020-00403-y

Frejd, D., Dunaway, K., Hill, J., Van Maanen, J., and Carlson, C. (2016). The genomic and morphological effects of bisphenol A on Arabidopsis thaliana. PloS One 11, 1-10. doi: 10.1371/journal.pone.0163028

Garg, N., and Manchanda, G. (2009). ROS generation in plants: Boon or bane? Plant Biosyst. 143, 81-96. doi: 10.1080/11263500802633626

Guo, J., Zhao, M. H., Shin, K. T., Niu, Y. J., Ahn, Y. D., Kim, N. H., et al. (2017). The possible molecular mechanisms of bisphenol A action on porcine early embryonic development. Sci. Rep. 7, 1-9. doi: 10.1038/s41598-017-09282-2
Hajiboland, R. (2014). "Reactive oxygen species and photosynthesis," in Oxidative Damage to Plants. Antioxidant Networks and Signaling. Ed. P. Ahmad (San Diego, CA, USA: Academic Press), 1-63.

Huang, H., Ullah, F., Zhou, D. X., Yi, M., and Zhao, Y. (2019). Mechanisms of ROS regulation of plant development and stress responses. Front. Plant Sci. 10, 110. doi: $10.3389 /$ fpls.2019.00800

Hüner, N. P. A., Bode, R., Dahal, K., Hollis, L., Rosso, D., Krol, M., et al. (2012). Chloroplast redox imbalance governs phenotypic plasticity: the "grand design of photosynthesis" revisited. Front. Plant Sci. 3, 255. doi: 10.3389/fpls. 2012.00255

Jalal, N., Surendranath, A. R., Pathak, J. L., Yu, S., and Chung, C. Y. (2018). Bisphenol A (BPA) the mighty and the mutagenic. Toxicol. Rep. 5, 76-84. doi: 10.1016/j.toxrep.2017.12.013

Jiao, L., Ding, H., Wang, L., Zhou, Q., and Huang, X. (2017). Bisphenol A effects on the chlorophyll contents in soybean at different growth stages. Environ. Pollut. 223, 426-434. doi: 10.1016/j.envpol.2017.01.042

Kang, J. H., and Kondo, F. (2006). Distribution and biodegradation of bisphenol A in water hyacinth. Bull. Environ. Contam. Toxicol. 77, 500-507. doi: 10.1007/ s00128-006-1092-x

Kim, D., Kwak, J.II, and An, Y. J. (2018). Effects of bisphenol A in soil on growth, photosynthesis activity, and genistein levels in crop plants (Vigna radiata). Chemosphere 209, 875-882. doi: 10.1016/j.chemosphere.2018.06.146

Laxa, M., Liebthal, M., Telman, W., Chibani, K., and Dietz, K. J. (2019). The role of the plant antioxidant system in drought tolerance. Antioxidants 8, 94. doi: 10.3390/antiox8040094

Li, X., Wang, L., Wang, S., Yang, Q., Zhou, Q., and Huang, X. (2018). A preliminary analysis of the effects of bisphenol $\mathrm{A}$ on the plant root growth via changes in endogenous plant hormones. Ecotoxicol. Environ. Saf. 150, 152158. doi: 10.1016/j.ecoenv.2017.12.031

Li, Y. T., Liang, Y., Li, Y. N., Che, X. K., Zhao, S. J., Zhang, Z. S., et al. (2018). Mechanisms by which Bisphenol A affect the photosynthetic apparatus in cucumber (Cucumis sativus L.) leaves. Sci. Rep. 8, 4253. doi: 10.1038/s41598018-22486-4

Lin, Z., Wang, L., Jia, Y., Zhang, Y., Dong, Q., and Huang, C. (2017). A Study on environmental bisphenol A pollution in plastics industry areas. Water Air Soil Pollut. 228, 98. doi: 10.1007/s11270-017-3277-9

Livanos, P., Galatis, B., Quader, H., and Apostolakos, P. (2012). Disturbance of reactive oxygen species homeostasis induces atypical tubulin polymer formation and affects mitosis in root-tip cells of Triticum turgidum and Arabidopsis thaliana. Cytoskeleton 69, 1-21. doi: 10.1002/cm.20538

Livanos, P., Galatis, B., and Apostolakos, P. (2016). Deliberate ROS production and auxin synergistically trigger the asymmetrical division generating the subsidiary cells in Zea mays stomatal complexes. Protoplasma 253, 10811099. doi: 10.1007/s00709-015-0866-6

Malea, P., Charitonidou, K., Sperdouli, I., Mylona, Z., and Moustakas, M. (2019). Zinc uptake, photosynthetic efficiency and oxidative stress in the seagrass Cymodocea nodosa exposed to $\mathrm{ZnO}$ nanoparticles. Materials 12, 2101. doi: 10.3390/ma12132101

Malea, P., Kokkinidi, D., Kevrekidou, A., and Adamakis, I. D. S. (2020). Environmentally relevant bisphenol A concentrations effects on the seagrass Cymodocea nodosa different parts elongation: perceptive assessors of toxicity. Environ. Sci. Pollut. Res. 27, 267-7279. doi: 10.1007/s11356-019-07443-6

Mignolet-Spruyt, L., Xu, E., Idänheimo, N., Hoeberichts, F. A., M̈hlenbock, P., Brosché, M., et al. (2016). Spreading the news: subcellular and organellar reactive oxygen species production and signaling. J. Exp. Bot. 67, 3831-3844. doi: $10.1093 / \mathrm{jxb} / \mathrm{erw} 080$

Mittler, R., Vanderauwera, S., Suzuki, N., Miller, G., Tognetti, V. B., Vandepoele, K., et al. (2011). ROS signaling: the new wave? Trends Plant Sci. 16, 300-309. doi: 10.1016/j.tplants.2011.03.007

Moura, M., De, dos Santos, L. S., and Van Houten, B. (2010). Mitochondrial dysfunction in neurodegenerative diseases and cancer. Environ. Mol. Mutagen. 405, 391-405. doi: 10.1002/em.20575

Moustaka, J., Tanou, G., Adamakis, I. D., Eleftheriou, E. P., and Moustakas, M. (2015). Leaf age dependent photoprotective and antioxidative mechanisms to paraquat-induced oxidative stress in. Arabidopsis Thaliana Int. J. Mol. Sci. 16, 13989-14006. doi: 10.3390/ijms160613989

Moustaka, J., Panteris, E., Adamakis, I. D. S., Tanou, G., Giannakoula, A., Eleftheriou, E. P., et al. (2018). High anthocyanin accumulation in poinsettia 
leaves is accompanied by thylakoid membrane unstacking, acting as a photoprotective mechanism, to prevent ROS formation. Environ. Exp. Bot. 154, 44-55. doi: 10.1016/j.envexpbot.2018.01.006

Moustakas, M., Malea, P., Zafeirakoglou, A., and Sperdouli, I. (2016). Photochemical changes and oxidative damage in the aquatic macrophyte Cymodocea nodosa exposed to paraquat-induced oxidative stress. Pest. Biochem. Physiol. 126, 28-34. doi: 10.1016/j.pestbp.2015.07.003

Moustakas, M., Malea, P., Haritonidou, K., and Sperdouli, I. (2017). Copper bioaccumulation, photosystem II functioning and oxidative stress in the seagrass Cymodocea nodosa exposed to copper oxide nanoparticles. Environ. Sci. Pollut. Res. 24, 16007-16018. doi: 10.1007/s11356-017-9174-3

Moustakas, M., Bayçu, G., Gevrek-Kürüm, N., Moustaka, J., Csatári, I., and Rognes, S. E. (2019a). Spatiotemporal heterogeneity of photosystem II function during acclimation to zinc exposure and mineral nutrition changes in the hyperaccumulator Noccaea caerulescens. Environ. Sci. Pollut. Res. 26, 6613-6624. doi: 10.1007/s11356-019-04126-0

Moustakas, M., Hanć, A., Dobrikova, A., Sperdouli, I., Adamakis, I. D. S., and Apostolova, E. (2019b). Spatial heterogeneity of cadmium effects on Salvia sclarea leaves revealed by chlorophyll fluorescence imaging analysis and laser ablation inductively coupled plasma mass spectrometry. Materials 12, 2953. doi: $10.3390 / \mathrm{ma} 12182953$

Mubarakshina, M. M., Ivanov, B. N., Naydov, I. A., Hillier, W., Badger, M. R., and Krieger-Liszkay, A. (2010). Production and diffusion of chloroplastic $\mathrm{H}_{2} \mathrm{O}_{2}$ and its implication to signalling. J. Exp. Bot. 61, 3577-3587. doi: 10.1093/jxb/erq171

Muranaka, L. S., Giorgiano, T. E., Takita, M. A., Forim, M. R., Silva, L. F. C., Coletta-Filho, H. D., et al. (2013). N-Acetylcysteine in agriculture, a novel use for an old molecule: focus on controlling the plant-pathogen. Xylella Fastidiosa. PloS One 8, e72937. doi: 10.1371/journal.pone.0072937

Noctor, G., and Foyer, C. H. (2016). Intracellular redox compartmentation and ROS-related communication in regulation and signaling. Plant Physiol. 171, 1581-1592. doi: 10.1104/pp.16.00346

Noctor, G., Reichheld, J. P., and Foyer, C. H. (2018). ROS-related redox regulation and signaling in plants. Semin. Cell Dev. Biol. 80, 3-12. doi: 10.1016/j.semcdb.2017.07.013

Noureddin, M. I., Furumoto, T., Ishida, Y., and Fukui, H. (2004). Absorption and metabolism of bisphenol A, a possible endocrine disruptor, in the aquatic edible plant, water convolvulus (Ipomoea aquatica). Biosci. Biotechnol. Biochem. 68, 1398-1402. doi: 10.1271/bbb.68.1398

Pan, W. J., Xiong, C., Wu, Q. P., Liu, J. X., Liao, H. M., Chen, W., et al. (2013). Effect of BPA on the germination, root development, seedling growth and leaf differentiation under different light conditions in Arabidopsis thaliana. Chemosphere 93, 2585-2592. doi: 10.1016/j.chemosphere.2013.09.081

Petrov, V. D., and Van Breusegem, F. (2012). Hydrogen peroxide-a central hub for information flow in plant cells. AoB Plants 2012, pls014. doi: 10.1093/aobpla/ pls014

Petrov, V., Hille, J., Mueller-Roeber, B., and Gechev, T. S. (2015). ROS-mediated abiotic stress-induced programmed cell death in plants. Front. Plant Sci. 6, 69. doi: $10.3389 /$ fpls.2015.00069

Potters, G., Horemans, N., and Jansen, M. A. K. (2010). The cellular redox state in plant stress biology - A charging concept. Plant Physiol. Biochem. 48, 292-300. doi: 10.1016/j.plaphy.2009.12.007

Qiu, Z., Wang, L., and Zhou, Q. (2013). Effects of bisphenol A on growth, photosynthesis and chlorophyll fluorescence in above-ground organs of soybean seedlings. Chemosphere 90, 1274-1280. doi: 10.1016/j.chemosphere.2012.09.085

Rapała, M., Pluciński, B., and Jedynak, P. (2017). The effect of bisphenol A on growth, pigment composition and photosystem II activity of Arabidopsis thaliana. Acta Biochim. Pol. 64, 407-413. doi: 10.18388/abp.2017_1626

Reis, A. R., Tabei, K., and Sakakibara, Y. (2014). Oxidation mechanism and overall removal rates of endocrine disrupting chemicals by aquatic plants. J. Hazard Mater. 265, 79-88. doi: 10.1016/j.jhazmat.2013.11.042

Ruano, G., and Scheuring, D. (2020). Plant cells under attack: Unconventional endomembrane trafficking during plant defense. Plants 9, 389. doi: 10.3390/plants9030389

Shafei, A., Ramzy, M. M., Hegazy, A. I., Husseny, A. K., EL-hadary, U. G., Taha, M. M., et al. (2018). The molecular mechanisms of action of the endocrine disrupting chemical bisphenol A in the development of cancer. Gene 647, 235-243. doi: 10.1016/j.gene.2018.01.016

Sperdouli, I., and Moustakas, M. (2012). Spatio-temporal heterogeneity in Arabidopsis thaliana leaves under drought stress. Plant Biol. 14, 118-128. doi: $10.1111 /$ j.1438-8677.2011.00473.x
Sperdouli, I., Moustaka, J., Antonoglou, O., Adamakis, I.-D. S., DendrinouSamara, C., and Moustakas, M. (2019). Leaf age-dependent effects of foliarsprayed CuZn nanoparticles on photosynthetic efficiency and ROS generation in Arabidopsis thaliana. Mater. (Basel) 12, 2498. doi: 10.3390/ma12152498

Staples, C. A., Dorn, P. B., Klečka, G. M., O’ Block, S. T., and Harris, L. R. (1998). A review of the environmental fate, effects and exposures of bisphenol A. Chemosphere 36, 2149-2173. doi: 10.1016/S0045-6535(97)10133-3

Staples, C., Friederich, U. R. S., Hall, T., Klečka, G., Mihaich, E., Ortego, L., et al. (2010). Estimating potential risks to terrestrial invertebrates and plants exposed to bisphenol A in soil amended with activated sludge biosolids. Environ. Toxicol. Chem. 29, 467-475. doi: 10.1002/etc.49

Stasolla, C., Huang, S., Hill, R. D., and Igamberdiev, A. U. (2019). Spatio-temporal expression of phytoglobin: a determining factor in the NO specification of cell fate. J. Exp. Bot. 70, 4365-4377. doi: 10.1093/jxb/erz084

Stavropoulou, K., Adamakis, I.-D. S., Panteris, E., Arseni, E.-M., and Eleftheriou, E. P. (2018). Disruption of actin filaments in Zea mays by bisphenol A depends on their crosstalk with microtubules. Chemosphere 195, 653-665. doi: 10.1016/ j.chemosphere.2017.12.099

Sun, H., Zhang, X., He, X., Ahmed, I. M., Cao, F., Zhang, G., et al. (2014). NAcetyl-cysteine alleviates $\mathrm{Cd}$ toxicity and reduces $\mathrm{Cd}$ uptake in the two barley genotypes differing in Cd tolerance. Plant Growth Regul. 74, 93-105. doi: 10.1007/s10725-014-9906-Z

Tian, Y. S., Jin, X. F., Fu, X. Y., Zhao, W., Han, H. J., Zhu, B., et al. (2014). Microarray analysis of differentially expressed gene responses to Bisphenol A in Arabidopsis. J. Toxicol. Sci. 39, 671-679. doi: 10.2131/jts.39.671

van Loon, L. C. (2016). The Intelligent Behavior of Plants. Trends Plant Sci. 21, 286-294. doi: 10.1016/j.tplants.2015.11.009

Wang, Q., Wang, L., Han, R., Yang, L., Zhou, Q., and Huang, X. (2015). Effects of bisphenol A on antioxidant system in soybean seedling roots. Environ. Toxicol. Chem. 34, 1127-1133. doi: 10.1002/etc.2904

Wilson, K. E., Ivanov, A. G., Öquist, G., Grodzinski, B., Sarhan, F., and Huner, N. P. A. (2006). Energy balance, organellar redox status, and acclimation to environmental stress. Can. J. Bot. 84, 1355-1370. doi: 10.1139/B06-098

Wu, F., Chi, Y., Jiang, Z., Xu, Y., Xie, L., Huang, F., et al. (2020). Hydrogen peroxide sensor HPCA1 is an LRR receptor kinase in Arabidopsis. Nature 578, 577-581. doi: 10.1038/s41586-020-2032-3

Xiao, C., Wang, L., Hu, D., Zhou, Q., and Huang, X. (2019). Effects of exogenous bisphenol A on the function of mitochondria in root cells of soybean (Glycine max L.) seedlings. Chemosphere 222, 619-627. doi: 10.1016/j.chemosphere.2019.01.195

Xiao, C., Wang, L., Zhou, Q., and Huang, X. (2020). Hazards of bisphenol A (BPA) exposure: A systematic review of plant toxicology studies. J. Hazard Mater. 384, 121488. doi: 10.1016/j.jhazmat.2019.121488

Xu, S. Y., Zhang, H., He, P. J., and Shao, L. M. (2011). Leaching behaviour of bisphenol A from municipal solid waste under landfill environment. Environ. Technol. 32, 1269-1277. doi: 10.1080/09593330.2010.535175

Zafarullah, M., Li, W. Q., Sylvester, J., and Ahmad, M. (2003). Molecular mechanisms of N-acetylcysteine actions. Cell. Mol. Life Sci. 60, 6-20. doi: 10.1007/s000180300001

Zhang, J., Li, X., Zhou, L., Wang, L., Zhou, Q., and Huang, X. (2016). Analysis of effects of a new environmental pollutant, bisphenol $\mathrm{A}$, on antioxidant systems in soybean roots at different growth stages. Sci. Rep. 6, 1-10. doi: 10.1038/srep23782

Zhang, C., Feng, Y., Liu, Y. W., Chang, H. Q., Li, Z. J., and Xue, J. M. (2017). Uptake and translocation of organic pollutants in plants: A review. J. Integr. Agric. 16, 1659-1668. doi: 10.1016/S2095-3119(16)61590-3

Zhang, J., Wang, L., Zhou, Q., and Huang, X. (2018). Reactive oxygen species initiate a protective response in plant roots to stress induced by environmental bisphenol A. Ecotoxicol. Environ. Saf. 154, 197-205. doi: 10.1016/j.ecoenv.2018.02.020

Conflict of Interest: The authors declare that the research was conducted in the absence of any commercial or financial relationships that could be construed as a potential conflict of interest.

Copyright (c) 2020 Adamakis, Sperdouli, Eleftheriou and Moustakas. This is an openaccess article distributed under the terms of the Creative Commons Attribution License (CC BY). The use, distribution or reproduction in other forums is permitted, provided the original author(s) and the copyright owner(s) are credited and that the original publication in this journal is cited, in accordance with accepted academic practice. No use, distribution or reproduction is permitted which does not comply with these terms. 